\title{
A Visual Inquiry Tool for Brand Identity
}

\author{
Dina Elikan \\ Department of Information Systems, \\ Faculty of HEC, University of Lausanne \\ dina.elikan@unil.ch
}

\begin{abstract}
Brand identity is of paramount importance for companies. Owing to the advancement of technology, faster innovation, growing competition, and more demanding consumers, managing a brand is becoming increasingly complex. This is especially true for entrepreneurs in startups and SMEs, who may not have the knowledge and various resources to ensure a clear branding strategy. This paper describes the development, in three steps, of a visual collaboration tool that supports practitioners in SMEs and startups to collaboratively strategize their brand identity in a structured way. This paper reports the creation, demonstration, and a first evaluation of what we have called the Brand Identity Tool.
\end{abstract}

\section{Introduction}

Brand identity is paramount for startups and SMEs owing to today's business realities, characterized by rapid advancement of technology, accelerated innovation, growing competition, and increasingly demanding consumers. Managing a brand has become increasingly complex [1];[2];[3];[4]. Despite its complexity, brand identity is a key construct that helps companies to define their purpose. And according to Sisodia et al., [5] organizations with a clear purpose can outperform their competition by up to fourteen times. It helps companies to differentiate themselves from competitors [6];[7]. It is by developing a specific brand identity that a company makes its brand unique and conveys its distinctness [8]. Used strategically, it guides brand decisions, guarantees the coherence of a marketing strategy over time, and should be associated with specific and limited core values that complement organizational values and culture [9];[10]. A clear brand identity strategy can be described as a narrative that defines a company's vision, inspires employees and other stakeholders, and remains relevant through changes.

\author{
Yves Pigneur \\ Department of Information Systems, \\ Faculty of HEC, University of Lausanne \\ yves.pigneur@unil.ch
}

Startups and SMEs must attract attention from both internal and external stakeholders in order to become and remain successful [11]. They need to communicate their purpose and identity in order to sell to their potential investors and customers, and to communicate consistently on social media. Rode and Vallaster [12] even state that startups that successfully develop an identity that aligns with their business concepts, values, and philosophy are more successful than startups that do not. When a startup successfully communicates this identity to its stakeholders and employees, it can develop a clear, distinct image [13]. Achieving a coherent brand identity strategy is difficult, since the branding concept may seem misty to entrepreneurs who cannot afford to have their branding strategy done externally. Merrilees [14] states that SME owners often think that creating and managing their brand is out of their reach. Because the topic concerns the organization as a whole, it involves different people, and is dynamic and evolves during an organization's lifetime [15]. But because practitioners without a marketing background may find the brand identity concept hard to grasp, they likely have different perspectives and definitions concerning the topic. Nonetheless, brand identity should form an integrative part of an organization's strategy [16], which should be the result of discussions and reflection between SME and startup founders and managers.

In this endeavor, visual inquiry tools typically support collaboration through structuring and allowing the shared visualization of a problem, allowing for a better shared understanding of this problem by different team members. This family of tools supports idea generation and the exploration of a specific problem, allowing team members to prototype and explore different potential solutions to the problem [1]. Thus, these tools are appropriate to the aforementioned situation, in which cross-disciplinary teams gather to strategize around a given ill-structured problem [17]. Further, Bork et al. [18] show how design approaches such as the uses of these tools are well suited to address such problems. Nonetheless, according to persons at the startups and SMEs we interviewed, who are active in 
different fields and who sought to strategize around their brand identity, doing so without the right knowledge is a challenge and, to date, very few tools support this endeavor.

Our goal here is to present the first steps of the development of a collaborative tool that seeks to help teams to collaboratively address their brand identity strategy. We seek to answer one generative question: How can we create a tool that helps startups and SMES to co-design their brand identity?

This paper makes two key contributions. First, we present a tool that helps practitioner teams to co-design their brand identity, conducting a preliminary evaluation of the artifact. Second, because this tool is part of a broader project, we report the detailed development steps of this tool. The remainder of this paper is organized following Gregor and Hevner's publication schema [19] for a Design Science Research Study.

\section{Theoretical Background}

\subsection{The brand identity concept}

The brand identity concept is has been looked at from many disciplines (marketing, organizational behavior, communication, strategy, etc.) [20], which could explain why it lacks a clear definition. Several authors agree that brand identity is hard to define (i.e. [21], [22], [23], [24]). From a strategy perspective, branding is seen as a key activity that must be managed, and that is constructed by different activities. In organizational behavior, scholars tend to look at brand identity to understand the relationships between the internal and external stakeholders with the organization.

Nonetheless, some definitions seem to recur in these disciplines. One approach was to define a brand as constituted by its components [25], but this led to new problems in the choice of these components. For instance, Aaker [6] as well as Harris and DeChernatony [26] define brand identity as the desired way an organization wants to be perceived by their targeted audience. Melewar et al. [27] define brand identity as the communication of a product or service's unique features to customers, which differentiates a brand from its competitors. These authors all claim that brand identity is central to a brand's strategic vision and that it supports the purpose and meaning of an organization's brand. According to Harris and DeChernatony [26], BI has six components: vision and culture, which drive the brand's desired positioning, personality and subsequent relationships, all of which are then presented to reflect stakeholders' current and aspirational self-images. Kapferer [28] showed that brand identity has six characteristics: physical, personality, culture, relationships, customer reflections, and customer selfimages. Already, between Kapferer's definition, which is widely accepted in marketing, and that of Harris and DeChernatony, we can see how different author definitions of the components of the same concept are.

According to Fetscherin and Usunier [29], a research gap underlies the fog in brand identity concepts' terminologies. This could be explained by the fact that this concept has not yet been articulated in conceptual models (i.e. ontologies), in which causality could be explained via flows. Despite this conceptual fog, at a more abstract level, there seems to be consensus between researchers in different fields - most authors agree that brand identity is the dynamic process of constructing and cultivating a positive image for an organization [30];[31];[15].

\subsubsection{Startups and SMEs}

The brand identity concept is especially important for startups and SMEs that are to be successful [12], because among others it will allow them to recruit employees with values aligned to the organization, which is more critical for startups and SMEs than for large corporations. Yet, branding activity can be seen as too costly for startups and SMEs and could therefore become a lower priority for them [32].

According to Spence and Hamzaoui [33], the main differences between BI for large organizations and for SMEs and startups are that, in large organizations, there is visionary management, while in smaller organizations, it is usually one individual with a vision (usually the entrepreneur); in a large organization, the process is very systematic, based on widespread market research, while, in smaller organizations, the process is more intuitive and based on an entrepreneur's values, personality, and perceptions.

\subsubsection{Strategizing on Brand identity}

Creating and maintaining a strong brand identity requires organizations to align three independent elements: vision, culture and image [34]. Since each element is driven by different consistencies, aligning them is a difficult but required exercise. Vision is the aspirations for the company, Culture encapsulates the organization's values, behaviors and attitudes employees feelings about company. And Image means the outside world's overall impression of the company. 
Because brand identity strategy encompasses so many different aspects, different people in the company should be involved [15]. A brand identity strategy should be the result of discussions, thoughts and iterations on potential strategies that could be put in place with all the key stakeholders, such as managers and founders of startups and SMEs.

\subsection{Visual inquiry tools}

Practitioner teams use of a variety of tools and objects to increase their capabilities when facing complexity and seeking to collaboratively solve a complex problem [35];[36];[37]. Collaborative tools support collaboration, because they allow practitioner teams to guide information-sharing, structuring and allowing for a shared understanding of a problem, increasing inquiry and idea generation, guiding and aligning team members' work, and motivating team members into participating and cooperating [38];[39]. Thus, work is now increasingly mediated by objects and tools used for purposes and functions [17].

Among these diverse tools, in recent years, we have seen an emergence of what we call visual inquiry tools to support the process of exploration, ideation, and prototyping solutions for a given wicked or illstructured problem. Examples include the Business Model Canvas [40], the Project Canvas [41], the Innovation Matrix [42], and the Customer Journey Map [43]. Such tools often take the form of shared and visual problem spaces in which teams can collectively explore and evaluate different hypotheses and potential solutions for a specific given wicked problem. These tools also allow practitioners to get a better perspective on a topic and to consider other members' perspectives, which according to Boland and Tenkasi [44] improves the possibilities of achieving innovation in an organization. The visual practices underlying the tools have been referred to as socio-material or visual practices [45], [46], and consists of jointly and iteratively visualizing facts, analyses, insights, and experiences, improving the quality of collaboration [47].

A visual inquiry tool is defined by Avdiji [48] as a tool that frames the elements of a wicked problem and represents them in a shared visual problem space that team members can use to inquire into the problem. As noted by Daalsgard [17], joint inquiry means that a practitioner team jointly, iteratively, and democratically explores and defines the problem they face and jointly develops and evaluates prototypes of potential solutions on how to solve it. In the case of brand identity strategy, because it is complex, involves the whole company and requires discussion among different people with different backgrounds, visual inquiry tools are adapted. We thus, are looking at how to develop a tool that aims at supporting teams of practitioners in co-designing their brand identity.

\section{Method}

This research is part of a broader project that follows a design science research (DSR) approach. DSR in information systems (IS) seeks to solve relevant classes of problems by building useful artifact types [49]. We follow Osterwalder and Pigneur [50], who state that IS researchers are best positioned to design strategic tools, given the IS tradition of designing artifacts.

We followed Peffers et al.'s [51] methodology to design and evaluate the Brand Identity Tool (BIT). This approach has six stages: identify the problem and motivate, define a solution's objectives, design and development, demonstration, evaluation, and communication. We elaborate on these stages in the following sections.

\subsection{Problem and motivation}

Brand identity is complex and hard to set up and manage for entrepreneurs of SMEs and startups, who usually don't have the resources and capabilities to define their brand identity, despite its importance [12], [14]. There has been an increase in the use of visual inquiry tools, which seem to be used by practitioner teams when facing a complex challenge that needs to be solved by different team members [18], [1]. To ensure this problem's relevance, this has been evaluated in a previous step of this design science project, and we conducted interviews with persons from startups and SMEs, to better understand their problems with brand identity and what requirements a tool that supports them in co-designing their brand identity had to meet.

\subsection{Objectives of the Tool}

Our objectives were: 1) to characterize the brand identity concept and structure it into an ontology, 2) to instantiate the ontology into a visual tool that captures and communicates the essence of brand identity, and 3) to offer a tool for practitioners who seek to define and manage their brand identity in teams.

\subsection{Designing and Developing the Tool}


We followed Avdiji et al. [1], according to whom there are three main principles to follow when designing such tools. The first is to design an ontology that captures the essence of and structures a concept. The second states that a conceptual model should be translated into a visual instantiation. The third principle states that the instantiation should be turned into a shared support tool that should be used as a problem space in which one can prototype solutions. The following sections will present these steps in details.

\subsection{Evaluating the Tool}

The evaluation was done using qualitative methods [52], in particular we have conducted case studies [53]. These were done on four cases: two startups, one in the domain of software engineering, one in the domain of creation of innovation audio-visual content and on two SMEs in the domain of food. The different teams were composed of at least one of the founders and a manager. They were asked to first discuss their brand identity strategy without any guidelines or support. In a second time, we gave them the brand identity visual tool and asked them to discuss their brand identity strategy with the support of the tool. This allowed us to evaluate the perceived ease-of-use and perceived usefulness of the tool. We will further present this in Section 5.

\section{Artifact Description}

As explained in Section 3.3.1, we followed the principles presented by Avdiji et al.'s [1] principle to design visual tools that seek to solve a specific problem. We consider the particular wicked problem of brand identity and have, in a previous design cycle of this project, developed an ontology via the elements found in a systematic literature review (SLR) (for a detailed version, see [54]). This SLR was conducted to find the components and relationships of the underlying brand identity concepts in order to develop a brand identity ontology. We found 1,592 papers, applying inclusion and exclusion criteria to assess the quality of the found papers and to ensure that they defined the brand identity concept. We retained 55 papers; of these, we considered 24 elements useful for inclusion in the brand identity ontology. To develop this ontology, we used Unified Foundational Ontology (UFO), an upper ontology, and used the language OntoUML to formally design it. This result formed part of a previous cycle of our design science project [55].

An ontology is usually designed for a specific purpose [56]. Because here the purpose is to develop a

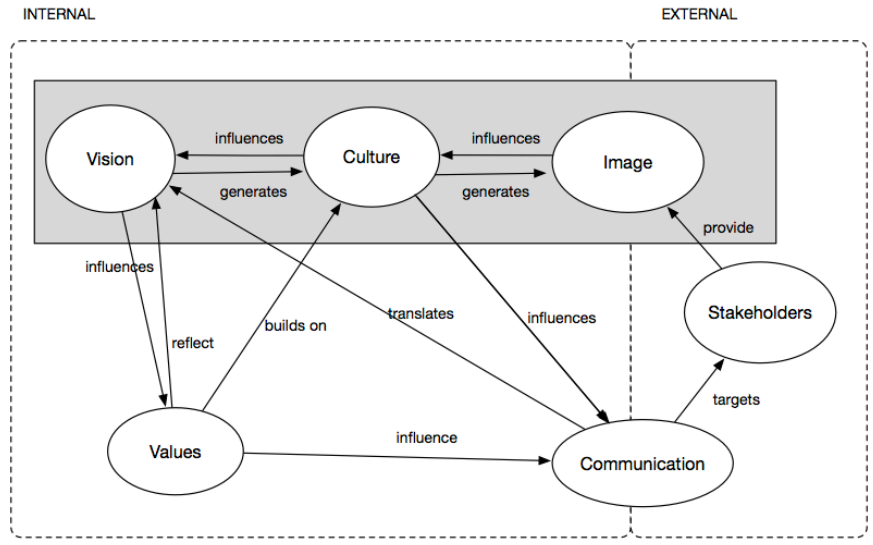

Figure 1. Simplified brand identity ontology

tool for practitioners, we simplified the ontology previously found. Figure 1 presents a simplified version of this ontology used for the development of the Brand Identity Tool. This ontology has two parts, internal and external, that refer to the inside of the company and its external environment.

From the previous step in the project to this simplified ontology, we removed some of the concepts found in the SLR. The SLR was built in order to better define the concept of brand identity, but having in mind the need of a co-design tool for practitioners, some concepts have been considered as not usable in the tool. Because the tool aims at supporting practitioners in developing and maintaining a strong brand identity, we looked at the found elements through the lens of Hatch and Schultz alignment's theory [57]. Thus, the most central elements are vision, culture and image, because it's through their alignment that an organization will achieve a strong brand identity. We have arranged all the found concepts around these three central elements and have sorted all the concepts. We have also only kept the concepts that were mutually exclusive and allowed the ontology to be exhaustive with the least amount of concept in order to keep it parsimonious. For instance, we had found a concept named visual elements, but it is in fact a more detailed element of the communication concept, we have thus removed that concept.

\subsection{How was the ontology derived into a first visual instantiation?}

To better understand how the ontology was instantiated into the visual, one must first understand each of the concepts in the ontology.

1. Vision is an internal element of an organization. It is the organization's long-term purpose, reason for existence, vision, and 
philosophy. It describes the starting point from which all the organization's activities are initiated. It will also generate a certain culture. (Internal element.)

2. Culture is a collective way of thinking, a collective feeling among internal stakeholders that results from values, culture strength and future directions, for instance, differentiators from competitors. It will also set some norms that will affect the employees' routine and habit at work. (Internal element.)

3. Values are the organization's ethical beliefs and principles. These values, mixed with all the beliefs and the ideologies present in an organization, form its personality. These values also impact on the stakeholders' relationships with the organization. They will highly influence the vision and culture. (Internal element.)

4. Communication refers to all the media used for communicating with all types of stakeholders, which will transform these different communications that combine to form an image. (Internal element with an external impact.)

5. Image is both internal and external to an organization. Some researchers see it as the way an organization would like outsiders to see it, while others see it as the ways different external stakeholders see it. Combining these two views, we state that image is a holistic view held by (internal or external) stakeholders of an organization and is the result of sensemaking by these stakeholders and communication by the organization of a projected picture of itself. It is also influenced by daily interactions between organizational members and external audiences. (External element.)

6. Stakeholders are different actors that all have interests in an organization (including customers, suppliers, partners, and so on). The main stakeholders are the customers who provide the value to the company, then the employees are the most important internal stakeholders since they create the value that will be delivered and then the other stakeholders are going to be different for each organizations, for startups at early stages venture capitalists might be important to consider, whereas in SMEs some suppliers might be key for the daily operations.

Because we seek to facilitate communication between users when talking about their organization's brand identity, we decided to represent the ontology into a shared visualization by logically structuring the components into a visual problem space. To do so, we first had to define which components to keep and if we were to retain or change their definitions. We then had to place these components into a space in a logical order, following and respecting the different relationships and interlinkages found in the ontology. Further, we had to simplify the tool so as to ensure visual impact and clarity [58]. We then represented the ontology's components as empty problem spaces that could support exploration, solution generation, and presentation. To increase the tool's affordance, we added some elements, such as guiding questions in each block to help practitioners use and understand the tool. We also used some visual cues to provide further support and facilitate the tool's use.

We developed this tool for use as a boundary object [59], with some directions for use. These are techniques thought of for joint inquiry [1],[58], including: 1) exploration, 2) hypothesis generation, and 3) presentation. 1.) Exploration: The tool and its use should stimulate practitioners and should guide them into inquiring, creating, and exchanging ideas, insights, and alternatives for solving a wicked problem. This is usually done by using the tool as a shared visual on which users use sticky notes, where each sticky note contains an idea. 2.) Once all these ideas are on the tool, users can develop, transform, and evaluate these different ideas in order to select some alternative to further discuss solutions to a wicked problem. 3.) In this process, there are some tangible marks (i.e. the sticky notes) that allow users to present and criticize techniques when discussing solutions.

\subsection{How did the visual instantiation evolve to this current version?}

This current version is the first iteration of the visual instantiation. Because broad concepts such as vision, image, culture, values might be hard to grasp and to define for stakeholders with different backgrounds, we decided the change the semantics of the elements to simplify them. The building block "what" refers to the vision of the organization, the "how" refers to how this vision will actually be operated on a daily basis through the organization's values and culture. The "why" is a further derivation of the vision and values of the founders, where they have to define their true purpose. "Communication" refers to how they communicate all these elements (i.e. which channels they use to reach their stakeholders) and the three right building blocks allow them to state what image they would like to project on their different stakeholders. 


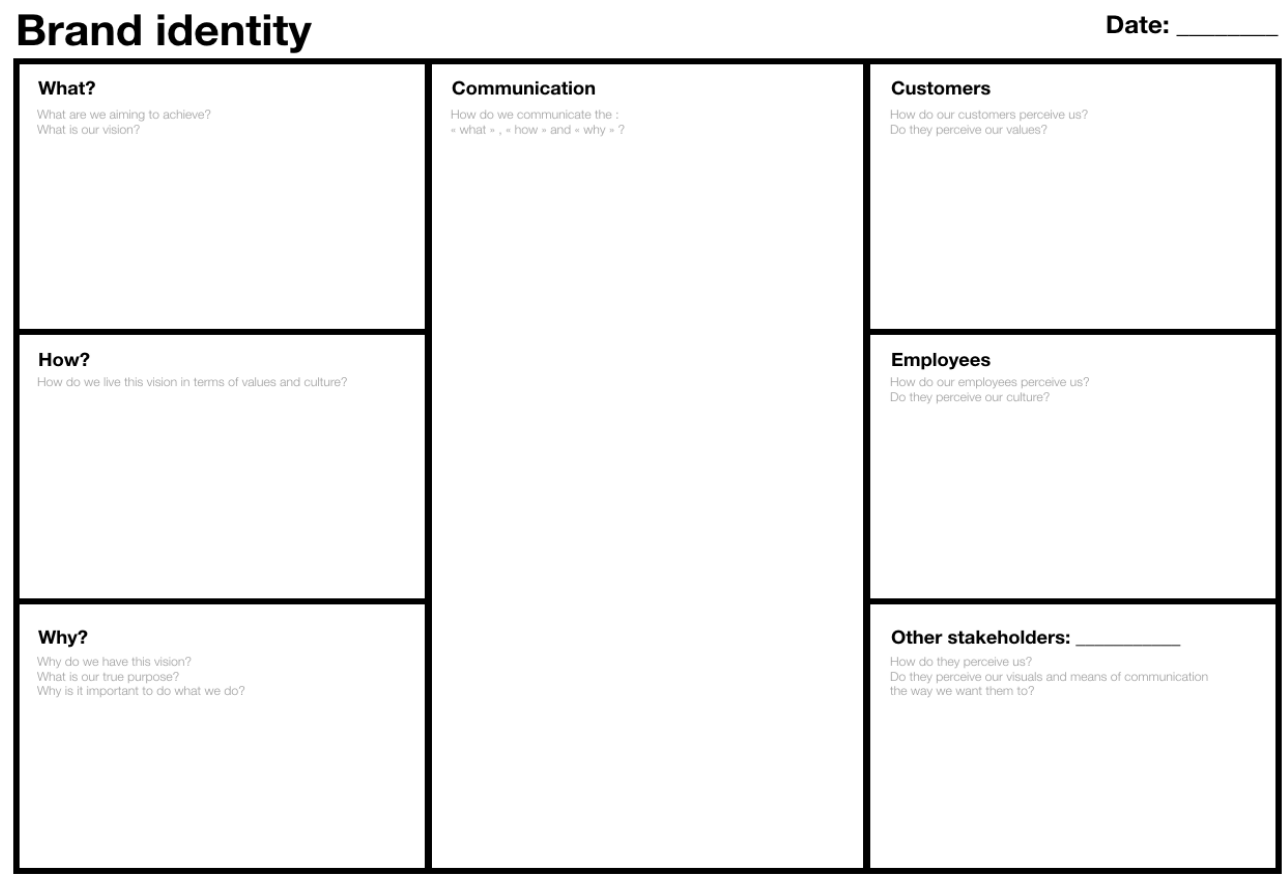

Figure 2. First iteration of the branding visual tool

\section{Evaluation of the Artefact}

To evaluate the tool, we conducted ex post evaluations in real settings; these were user opinion studies [60]. We interviewed persons from two SMEs in the food industry in Switzerland and two startups, one in digital and innovative audio-visual content creation and the other in software engineering. In each evaluation, the tool was used as a boundary object [61] to allow all team members to jointly explore a problem and discuss potential solutions.

\begin{tabular}{|l|l|l|l|l|}
\hline & $\begin{array}{l}\text { Organiz } \\
\text { ation 1 }\end{array}$ & $\begin{array}{l}\text { Organizati } \\
\text { on 2 }\end{array}$ & $\begin{array}{l}\text { Organiz } \\
\text { ation 3 }\end{array}$ & $\begin{array}{l}\text { Organiza } \\
\text { tion 4 }\end{array}$ \\
\hline Sector & $\begin{array}{l}\text { Audiovi } \\
\text { sual }\end{array}$ & Food & Food & Software \\
\hline $\begin{array}{l}\text { Year } \\
\text { funded }\end{array}$ & 2013 & 2014 & 2009 & 2017 \\
\hline $\begin{array}{l}\text { Employ } \\
\text { ees } \\
\text { number }\end{array}$ & $\begin{array}{l}11, \quad 3 \\
\text { founders }\end{array}$ & $\begin{array}{l}18 \text { full-time, } \\
\text { some part } \\
\text { time, 2 } 2 \\
\text { founders }\end{array}$ & $\begin{array}{l}>50 \text { full } \\
\text { time, 1 } \\
\text { founder }\end{array}$ & 3 \\
\hline
\end{tabular}

Table 1. Overview of the cases

We kept the settings similar for all the cases, gathering together persons involved in strategy (founders, CEO, partners, or persons in similar positions).
The workshop had two steps: the first was for the team to discuss their brand identity without our tool. Thus, teams would discuss what they thought their brand identity was and tried to define and explain it to the facilitator. In step 2, when they felt step 1 was complete, we would introduce the BIT on the wall and distribute pens and sticky notes to the practitioner teams. They would inquire, as a team, on their brand identity, this time guided and supported by the tool. We wanted to first evaluate our tool's potential efficacy and our ontology's completeness. After they had completed step 2 , we interviewed the practitioners to test the tool's perceived benefits and its ease-of-use.

Because the ontology is hard to present to practitioners and difficult to understand for them, including its usefulness, we decided to evaluate the ontology's completeness at the same time as evaluating the visual tool, by introducing the two-step workshops, which allowed us to compare a team's conversations with and without the tool, noticing if more topics were covered without the tool, which would prove the ontology's incompleteness.

For the sake of space, we will present here in details only two out of the four evaluations we conducted. The first one is "organization 1", they create innovative audio visual content for different types of customer segments. The three founders have no management or marketing background. When they were asked to 
discuss their brand identity, they all had different ways of looking at it. One of their main issue being the fact that they have customers from different backgrounds, for instance one month they had a project in the luxury watched industry and at the same time a project with an ONG in Syria. Once we presented the tool, they started the discussion again around the different elements, the results are shown in Appendix 1. In this discussion they realized that accepting projects in large corporations might be against some of their values, because ethics seemed to be important for all three of them. They also realized that the image they want to show their employees might not be aligned with the one their employees actually have. After these discussions the team said, "the tool allowed us to discuss topics that are often not discussed when we are lost in our daily routine".

The second evaluation was conducted on a Mexican food company "organization 2" that was founded by two brothers. They told us during the discussion that they had tried to come up with an explicit document for their brand identity because one of their employee in charge of marketing had made a marketing campaign that they considered as racist, and at that point they realized they did not manage to explain their vision to their employees. They found their discussion more focused and interesting with the support of the tool and stated: "we could consider using this tool to present our brand identity when recruiting new employees".

\begin{tabular}{|l|l|l|l|}
\hline Org & $\begin{array}{l}\text { Perceived usefulness of the } \\
\text { tool by the team }\end{array}$ & $\begin{array}{l}\text { Mana } \\
\text { ged to } \\
\text { use it }\end{array}$ & $\begin{array}{l}\text { Would } \\
\text { further } \\
\text { use it? }\end{array}$ \\
\hline 1 & $\begin{array}{l}\text { Good overview, brings a } \\
\text { structure in one single page that } \\
\text { helps strategize about brand } \\
\text { identity }\end{array}$ & Yes & Yes \\
\hline 3 & $\begin{array}{l}\text { Having a given structure helps } \\
\text { find the relevant points to } \\
\text { discuss }\end{array}$ & $\begin{array}{l}\text { Usefulfor small teams but could } \\
\text { be difficult to use for big teams } \\
\text { as maybe the workshop would } \\
\text { become messy. Are going to } \\
\text { further use it. }\end{array}$ & Yes \\
\hline 4 & $\begin{array}{l}\text { Unfamiliar with some of the } \\
\text { used vocabulary, some elements } \\
\text { should be clearer, not sure in } \\
\text { which context the tool would } \\
\text { actually be used }\end{array}$ & Yes & Probably \\
\hline
\end{tabular}

Table 2. Summary of the evaluation's results

Even if further evaluations should be conducted, in all our four cases the practitioners told us that they had found their discussion to be more interesting and on point when using the tool. We have thus validated the tool's perceived usefulness. In all four cases, the practitioners managed to use the tool to describe and demonstrate their brand identity strategy and told us it had been completely understandable and simple to use; thus, also the tool's ease-of-use was validated.

\section{Discussion}

Developing and maintaining a strong brand identity is essential for startups and SMEs [14],[13]. With a proper brand identity strategy, smaller organizations can improve their identity and the way they communicate the value they create for their users and other stakeholders [62]. It allows them to differentiate themselves from competitors [6], [63]. Also, it can help them to increase employee motivation, besides attracting qualified candidates and bigger investments [64]. These are vital for startups and SMEs that may not have the resources to attract adequate qualified human capital. Further, having a consistent brand identity can help them to plan a coherent social media strategy and to have a coherent online image.

However, strategizing a brand identity implies indepth knowledge of the topic and of the factors that may influence it. Da Silveira et al. [14] suggest that brand identity management is a dynamic process, and that the practitioners in charge should reshape brand identity over time, according to mhow the organization's environment changes. This is typically feasible with the help of a visual tool that would allow teams to inquire about brand identity before implementing their strategy. This tool should allow practitioners to have a shared visual and a shared understanding of their brand identity strategy. It should support and guide them towards explorations and discussions about potential brand identity strategies. For startups and SMEs that would like to use design tools to solve their problems, this would complement tools such as the Business Model Canvas [40], the Value Proposition Canvas, [65] and the Team Alignment Map [66]. These new generations of tools have proved useful for different reasons, such as solving a given problem and for presenting a strategy. As Kernbach et al. [67] note, visualization is more efficient than text when presenting a new business strategy. Thus, one could imagine presenting a brand identity strategy to a board or to employees with the visual support of this tool, instead of simply presenting a written text document.

\subsection{Future Evaluations}

Because evaluation is key to DSR [66], further work includes continuing the evaluation; we aim to increase the number of evaluations in startups and SMEs, which 
should allow us to refine the BIT. In these future evaluations, we have may perform $\mathrm{A} / \mathrm{B}$ experiments in which we place startups and SMEs in control and treatment conditions in order to better understand if we have addressed all the concepts that need to be addressed when talking about brand identity, but also to test whether using the tool adds value. Adding to that, in all of our current evaluations, users told us that if some of the elements they had in the "what" "how" and "why" building blocks were not coherent, there was no visual way to see it. They also said that the fact that these need to be aligned is not clear. We will thus try to work on a better visual instantiation in order to allow practitioners to better see the need to align these elements.

\section{Concluding Remarks}

We began this paper by asking: How can we create a tool that helps startups and SMEs to co-design their brand identity? We addressed this question by demonstrating how we developed the Brand Identity Tool. As Avdiji et al. [1] note, there are three design principles for developing such a tool: 1) Frame the problem into an ontology in which the main components and their relationships are modeled. 2) Represent this ontology into a shared visualization. 3) Instantiate it into a shared support tool, in order to use it as a problem space in which solutions can be prototyped. We have sought to demonstrate how we applied these principles to develop our artefact; our evaluations indicate satisfactory results. But, as Thomas Edison said, There is a way to do it better; find it! The presented tool is still in an iterative phase, and we plan to further improve it.

\section{References}

[1] H. Avdiji, D. Elikan, S. Missonier, and Y. Pigneur, "Designing Tools for Collectively Solving Ill-Structured Problems," presented at the 51st Hawaii International Conference on System Sciences - 2018, 2018.

[2] J. M. Balmer, "Identity based views of the corporation: Insights from corporate identity, organisational identity, social identity, visual identity, corporate brand identity and corporate image," Eur. J. Mark., vol. 42, no. 9/10, pp. 879-906, 2008.

[3] R. Abratt and N. Kleyn, "Corporate identity, corporate branding and corporate reputations: Reconciliation and integration," Eur. J. Mark., vol. 46, no. 7/8, pp. 1048-1063, 2012.

[4] P. Klaus and S. Maklan, "The role of brands in a service-dominated world," J. Brand Manag., vol. 15, no. 2, pp. 115-122, 2007.

[5] D. A. Aaker, "Measuring brand equity across products and markets," Calif. Manage. Rev., vol. 38, no. 3, pp. 102 120, 1996.

[6] J. N. Kapferer, The New Strategic Brand
Management: Creating and Sustaining Brand Equity Long Term. Kogan Page, 2004.

[7] R. K. Srivastava and A. D. Shocker, Brand equity: a perspective on its meaning and measurement. Marketing Science Institute, 1991.

[8] L. De Chernatony, "A model for strategically building brands," J. Brand Manag., vol. 9, no. 1, pp. 32-44, 2001.

[9] M. Urde, "Core value-based corporate brand building," Eur. J. Mark., vol. 37, no. 7/8, pp. 1017-1040, 2003.

[10] S. Bresciani and M. J. Eppler, "Brand new ventures? Insights on start-ups' branding practices," J. Prod. Brand Manag., vol. 19, no. 5, pp. 356-366, 2010.

[11] V. Rode and C. Vallaster, "Corporate branding for start-ups: The crucial role of entrepreneurs," Corp. Reput. Rev., vol. 8, no. 2, pp. 121-135, 2005.

[12] T. Muhonen, S. Hirvonen, and T. Laukkanen, "SME Brand identity: Its components, and performance effects," $J$. Prod. Brand Manag., vol. 26, no. 1, 2017.

[13] B. Merrilees, "A theory of brand-led SME new venture development," Qual. Mark. Res. Int. J., vol. 10, no. 4, pp. 403-415, 2007.

[14] C. Da Silveira, C. Lages, and C. Simões, "Reconceptualizing brand identity in a dynamic environment," J. Bus. Res., vol. 66, no. 1, pp. 28-36, 2013.

[15] S. Madhavaram, V. Badrinarayanan, and R. E. McDonald, "Integrated marketing communication (IMC) and brand identity as critical components of brand equity strategy: A conceptual framework and research propositions," $J$. Advert., vol. 34, no. 4, pp. 69-80, 2005.

[16] P. Dalsgaard, "Instruments of inquiry: Understanding the nature and role of tools in design," Int. J. Des., vol. 11, no. $1,2017$.

[17] D. Bork, D. Karagiannis, and I. T. Hawryszkiewycz, "Supporting Customized Design Thinking Using a Metamodel-based Approach,” 2017.

[18] J. M. Balmer and J. M. Balmer, "Corporate identity, corporate branding and corporate marketing-seeing through the fog," Eur. J. Mark., vol. 35, no. 3/4, pp. 248-291, 2001.

[19] L. De Chernatony, "Towards the holy grail of definingbrand'," Mark. Theory, vol. 9, no. 1, pp. 101-105, 2009.

[20] B. B. Stern, "What doesbrand mean? historicalanalysis method and construct definition," J. Acad. Mark. Sci., vol. 34, no. 2, pp. 216-223, 2006.

[21] L. Wood, "Brands and brand equity: definition and management," Manag. Decis., vol. 38, no. 9, pp. 662-669, 2000.

[22] J. M. Balmer and J. M. Balmer, "Corporate identity, corporate branding and corporate marketing-seeing through the fog," Eur. J. Mark., vol. 35, no. 3/4, pp. 248-291, 2001.

[23] L. De Chernatony and F. Dall'Olmo Riley, "Defining a' brand': Beyond the literature with experts' interpretations," J. Mark. Manag., vol. 14, no. 5, pp. 417-443, 1998.

[24] F. Harris and L. de Chernatony, "Corporate branding and corporate brand performance," Eur. J. Mark., vol. 35, no. 3/4, pp. 441-456, 2001.

[25] T. Melewar, M. Gotsi, C. Andriopoulos, M. Fetscherin, and J.-C. Usunier, "Corporate branding: An interdisciplinary literature review," Eur. J. Mark., vol. 46, no. 5, pp. 733-753, 2012. 
[26] J.-N. Kapferer, "Corporate brand and organizational identity," Corp. Organ. Identities Integrating Strategy Mark. Commun. Organ. Perspect., pp. 175-194, 2002.

[27] M. Fetscherin and J.-C. Usunier, "Corporate branding: An interdisciplinary literature review," Eur. J. Mark., vol. 46, no. 5, pp. 733-753, 2012.

[28] S. Einwiller and M. Will, "Towards an integrated approach to corporate branding-an empirical study," Corp. Commun. Int. J., vol. 7, no. 2, pp. 100-109, 2002.

[29] C. B. Van Riel and G. H. Van Bruggen, "Incorporating business unit managers' perspectives in corporate-branding strategy decision making," Corp. Reput. Rev., vol. 5, no. 2-3, pp. 241-251, 2002.

[30] A. P. Petkova, V. P. Rindova, and A. K. Gupta, "How can new ventures build reputation? An exploratory study," Corp. Reput. Rev., vol. 11, no. 4, pp. 320-334, 2008.

[31] M. Spence and L. Hamzaoui Essoussi, "SME brand building and management: an exploratory study," Eur. J. Mark., vol. 44, no. 7/8, pp. 1037-1054, 2010.

[32] P. Dalsgaard, "Instruments of inquiry: Understanding the nature and role of tools in design," Int. J. Des., vol. 11, no. $1,2017$.

[33] K. K. Cetina, "Sociality with objects: Social relations in postsocial knowledge societies," Theory Cult. Soc., vol. 14, no. 4, pp. 1-30, 1997.

[34] K. Lindberg and L. Walter, "Objects-in-use and organizing in action nets: A case of an infusion pump," $J$. Manag. Inq., vol. 22, no. 2, pp. 212-227, 2013.

[35] D. Nicolini, J. Mengis, and J. Swan, "Understanding the role of objects in cross-disciplinary collaboration," Organ. Sci., vol. 23, no. 3, pp. 612-629, 2012.

[36] G. A. Okhuysen and B. A. Bechky, "10 coordination in organizations: An integrative perspective," Acad. Manag. Ann., vol. 3, no. 1, pp. 463-502, 2009.

[37] A. Osterwalder and Y. Pigneur, Business model generation: a handbook for visionaries, game changers, and challengers. John Wiley \& Sons, 2010.

[38] F. Habermann and K. Schmidt, "The project canvas. A visual tool to jointly understand, design, and initiate projects," 2014.

[39] P. Van Der Pijl, J. Lokitz, and L. K. Solomon, Design a better business: new tools, skills, and mindset for strategy and innovation. John Wiley \& Sons, 2016.

[40] J. Kalbach, Mapping experiences: A complete guide to creating value through journeys, blueprints, and diagrams. O'Reilly Media, Inc., 2016.

[41] R. J. Boland Jr and R. V. Tenkasi, "Perspective making and perspective taking in communities of knowing," Organ. Sci., vol. 6, no. 4, pp. 350-372, 1995.

[42] J. K. Whyte, B. Ewenstein, M. Hales, and J. Tidd, "Visual practices and the objects used in design," Build. Res. Inf., vol. 35, no. 1, pp. 18-27, 2007.

[43] D. Nicolini, "Studying visual practices in construction," Build. Res. Inf., vol. 35, no. 5, pp. 576-580, 2007.

[44] M. J. Eppler and S. Bresciani, "Visualization in management: From communication to collaboration. A response to Zhang," J. Vis. Lang. Comput., vol. 24, no. 2, pp. 146-149, 2013.

[45] H. Avdiji, "Supporting the challenges of crossboundary teamwork through Design Science Research,"
THÈSE DE DOCTORAT, Université de Lausanne, Lausanne, 2018.

[46] R. H. Von Alan, S. T. March, J. Park, and S. Ram, "Design science in information systems research," MIS $Q$., vol. 28, no. 1, pp. 75-105, 2004.

[47] A. Osterwalder and Y. Pigneur, "Designing business models and similar strategic objects: the contribution of IS," J. Assoc. Inf. Syst., vol. 14, no. 5, p. 237, 2013.

[48] K. Peffers, T. Tuunanen, M. A. Rothenberger, and S. Chatterjee, "A design science research methodology for information systems research," J. Manag. Inf. Syst., vol. 24, no. 3, pp. 45-77, 2007.

[49] D. Elikan and Y. Pigneur, "Foundations of a visual tool for brand identity," presented at the European Conference on Information Systems 2018 (ECIS), Proceedings, Porthsmouth, UK, 2018.

[50] D. Elikan and Y. Pigneur, "Towards a brand identity ontology." 2018.

[51] A. Gomez-Perez, M. Fernández-López, and O. Corcho, Ontological Engineering: with examples from the areas of Knowledge Management, e-Commerce and the Semantic Web. Springer Science \& Business Media, 2006.

[52] S. Bresciani, A. F. Blackwell, and M. Eppler, "A Collaborative Dimensions Framework: Understanding the mediating role of conceptual visualizations in collaborative knowledge work," presented at the Hawaii International Conference on System Sciences, Proceedings of the $41 \mathrm{st}$ Annual, 2008, pp. 364-364.

[53] J. Pries-Heje, R. Baskerville, and J. R. Venable, "Strategies for Design Science Research Evaluation.," presented at the ECIS, 2008, pp. 255-266.

[54] P. R. Carlile, "A pragmatic view of knowledge and boundaries: Boundary objects in new product development," Organ. Sci., vol. 13, no. 4, pp. 442-455, 2002.

[55] R. R. Gehani, "Corporate Brand Value Shifting from Identity to Innovation Capability: from Coca-Cola to Apple," J. Technol. Manag. Innov., vol. 11, no. 3, pp. 11-20, 2016.

[56] J.-N. Kapferer, The new strategic brand management: Advanced insights and strategic thinking. Kogan page publishers, 2012.

[57] S. Arendt and M. Brettel, "Understanding the influence of corporate social responsibility on corporate identity, image, and firm performance," Manag. Decis., vol. 48, no. 10, pp. 1469-1492, 2010.

[58] A. Osterwalder, Y. Pigneur, G. Bernarda, and A. Smith, Value proposition design: how to create products and services customers want. John Wiley \& Sons, 2014.

[59] S. Mastrogiacomo, S. Missonier, and R. Bonazzi, "Talk before it's too late: reconsidering the role of conversation in information systems project management," $J$. Manag. Inf. Syst., vol. 31, no. 1, pp. 47-78, 2014.

[60] S. Kernbach, M. J. Eppler, and S. Bresciani, "The use of visualization in the communication of business strategies: An experimental evaluation," Int. J. Bus. Commun., vol. 52, no. 2, pp. 164-187, 2015.

[61] J. Venable, J. Pries-Heje, and R. Baskerville, "A comprehensive framework for evaluation in design science research," presented at the International Conference on Design Science Research in Information Systems, 2012, pp. 423-438. 
APPENDIX 1: Illustration of the first Evaluation of the Tool (Startup)

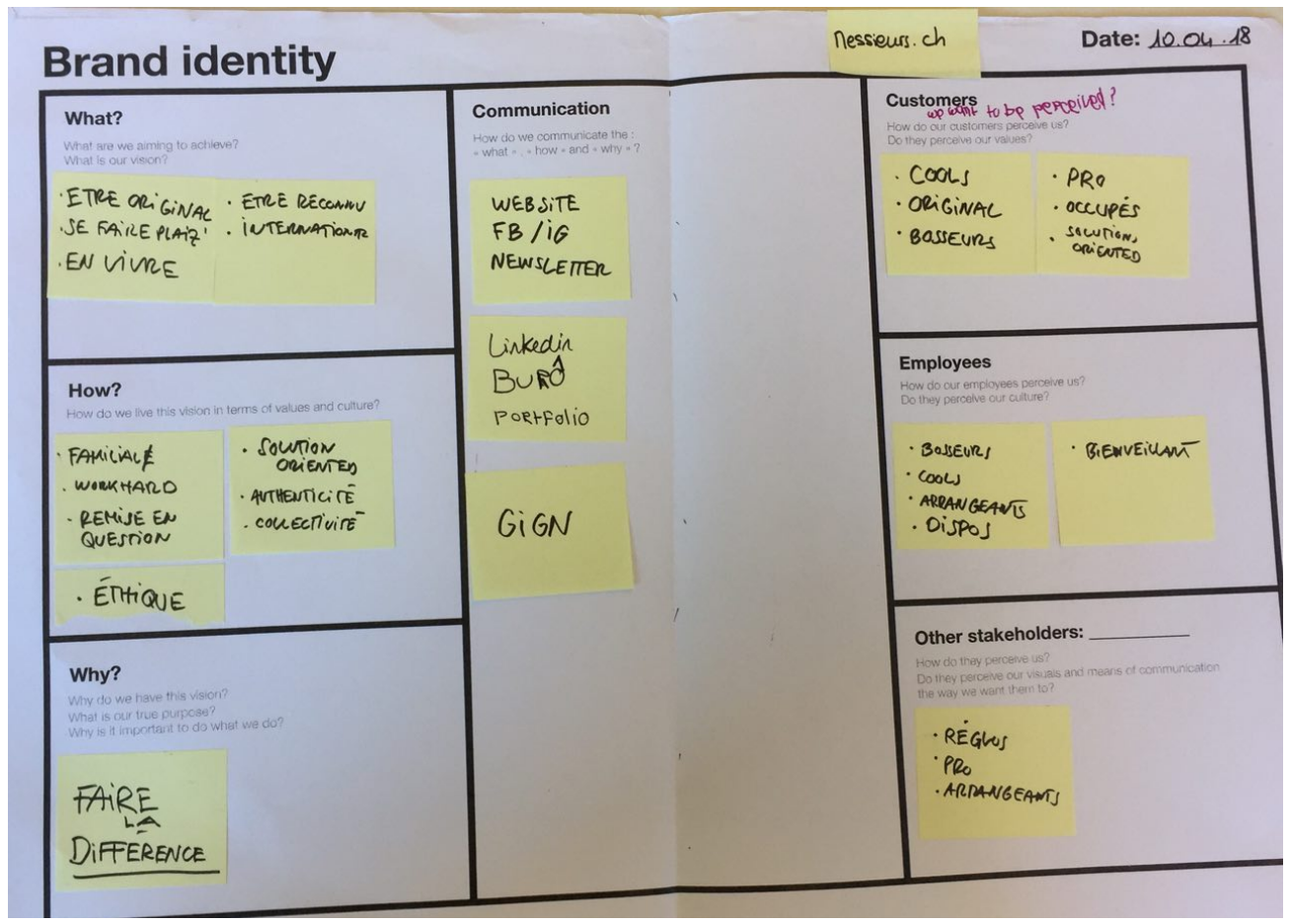

\section{APPENDIX 2: Illustration of the Evaluation of the Tool (SME)}

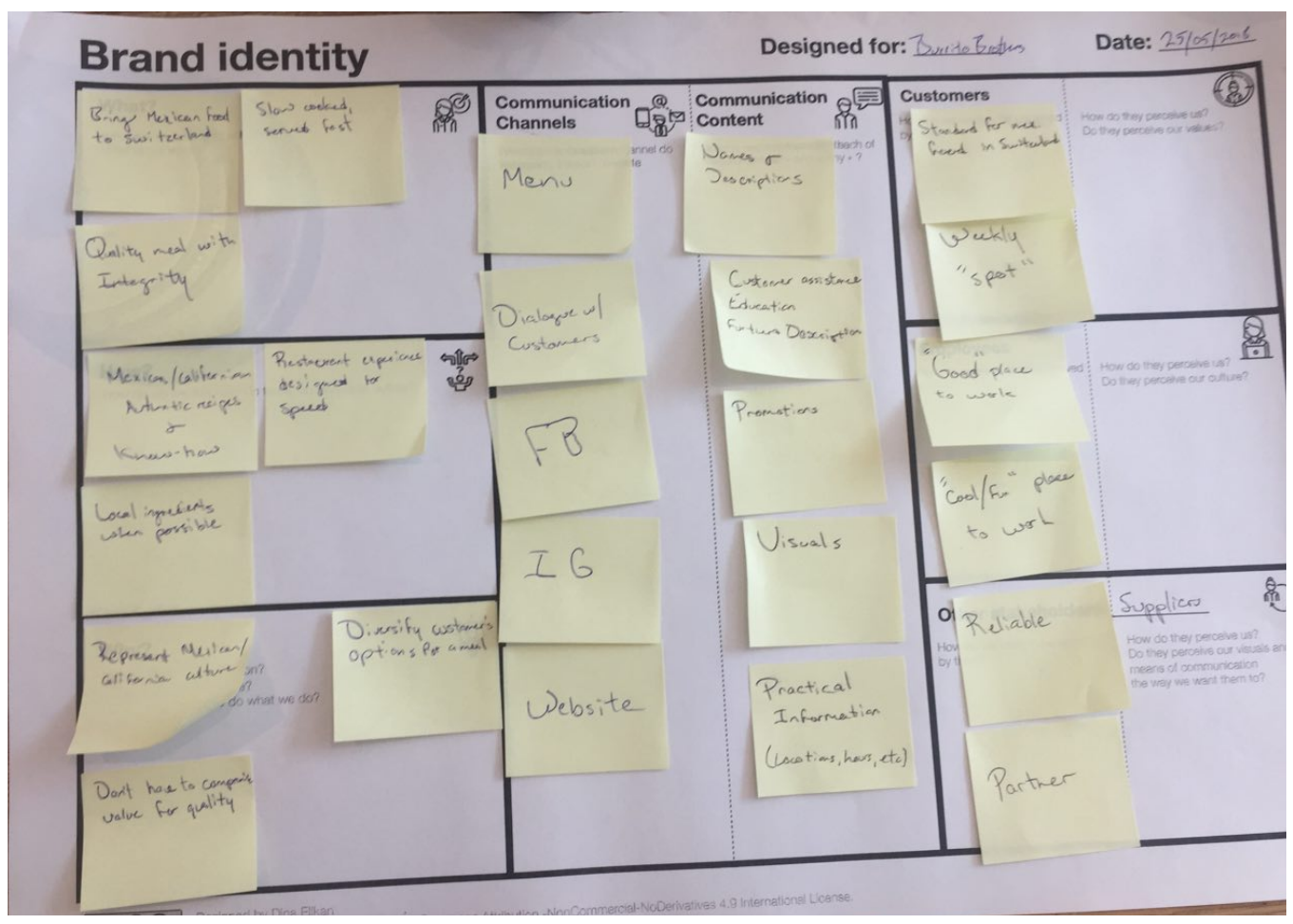

